\title{
ANALYSIS OF THE VANE TEST CONSIDERING SIZE AND TIME EFFECTS
}

\author{
A. PÉREZ-FOGUET, A. LEDESMA AND A. HUERTA* \\ Escuela Técnica Superior de Ingenieros de Caminos, Universitat Politècnica de Catalunya (UPC), Jordi Girona 1-3, \\ 08034 Barcelona, Spain
}

\begin{abstract}
SUMMARY
An analysis of the vane test using an Arbitrary Lagrangian-Eulerian formulation within a finite element framework is presented. This is suitable for soft clays for which the test is commonly used to measure in situ undrained shear strength. Constitutive laws are expressed in terms of shear stress-shear strain rates, and that permits the study of time effects in a natural manner. An analysis of the shear stress distributions on the failure surface according to the material model is presented. The effect of the constitutive law on the shear band amplitude and on the position of the failure surface is shown. In general, the failure surface is found at $1-1.01$ times the vane radius, which is consistent with some experimental results. The problem depends on two dimensionless parameters that represent inertial and viscous forces. For usual vane tests, viscous forces are predominant, and the measured shear strength depends mainly on the angular velocity applied. That can explain some of the comparisons reported when using different vane sizes. Finally, the range of the shear strain rate applied to the soil is shown to be fundamental when comparing experimental results from vane, triaxial and viscosimeter tests. Appart from that, an experimental relation between undrained shear strength and vane angular velocity has been reproduced by this simulation.
\end{abstract}

Key words: Arbitrary Lagrangian-Eulerian formulation; finite element method; soft materials; failure analysis; dimensionless analysis; viscous models

\section{INTRODUCTION}

The vane shear test has been used extensively from the 1950s to measure the in situ shear strength of soft clays, due to the simplicity of the test and to the difficulties in obtaining undisturbed samples in these materials. In fact most site investigation manuals and codes of practice in geotechnical engineering include a description of the vane equipment and some recommendations for its use. ${ }^{1,2}$ Also, the vane test has been useful in characterizing the in situ behaviour of very soft materials like slurried mineral wastes and in the determination of the viscosity of plastic fluids in laboratory tests. ${ }^{3,4}$ However, in spite of its common use, the interpretation of the vane test has been quite often a controversial issue. The work presented by Donald et al. ${ }^{5}$ summarizes the main drawbacks of the test and the usual sources of error in the estimation of the undrained strength: soil anisotropy effects, strain rate effects, and progressive failure. Classical interpretation of vane results did not take into account those effects. To overcome these difficulties, some

*Correspondence to: Antonio Huerta: Dept. de Matematica Aplicada III, E. T.S. de Ingenieros de Caminos, Universitat Politècnica de Catalunya (UPC), Jordi Girona 1-3, E-08034 Barcelona, Spain. E-mail: huerta@lacan.upc.es

*Contract grant sponsor: CICYT; contract grant number: TAP98-0421 
research has been devoted to the experimental analysis of the vane test in the laboratory or in the field: Menzies and Merrifield ${ }^{6}$ measured shear stresses in the vane blades, and Matsui and $\mathrm{Abe}^{7}$ measured normal stresses and pore pressures in the failure surface. Also Kimura and Saitoh ${ }^{8}$ obtained pore water pressure distributions from transducers located in the vane blades.

On the other hand, numerical simulations of the vane test are scarce, due to its mathematical complexity. Donald et al. ${ }^{5}$ presented a three-dimensional (3D) finite element analysis of the vane using a linear elastic constitutive model. Matsui and $\mathrm{Abe}^{7}$ also compared their experimental results with a coupled $2 \mathrm{D}$ finite element simulation using a strain-hardening model. More recently, De Alencar et al. ${ }^{9}$ and Griffiths and Lane ${ }^{10}$ have presented $2 \mathrm{D}$ finite element simulations of the vane with a strain-softening constitutive law. The latter also showed stress distributions in a quasi-3D analysis. These experimental and numerical reports have improved the knowledge of the stress distributions around the failure surface and therefore have contributed to an improvement on the interpretation of the vane test. Nevertheless, there is still some concern about the validity of the undrained strength $\left(s_{\mathrm{u}}\right)_{\text {vane }}$ obtained in this way. Bjerrum ${ }^{11}$ proposed a correction factor for the vane undrained strength which decreased with plasticity index. Also Bjerrum proposed to extend the procedure considering two correction factors in order to take into account anisotropy and time effects. That correction has been improved using information from case histories of embankment failures. ${ }^{12}$ Despite this correction factor, important differences between corrected $\left(s_{\mathrm{u}}\right)_{\mathrm{vane}}$ and undrained shear strength measured with independent tests have been reported for some clays. ${ }^{13-15}$ The contradictory results presented by different authors show that conceptual analyses of the vane test are still required to establish the validity of the test. As

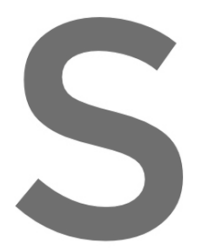
there are several facto neously. Even some uncertainties involv Recently, a new mos presented. $^{17,18}$ Recent concepts have been comparing theoretical and not E DI have defined a correction factor similar to that proposed by Bjerrum, although more elaborated.

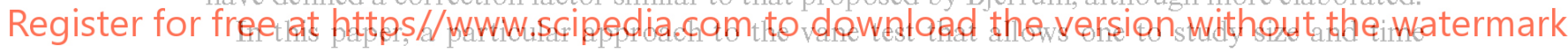
effects in a natural way is presented. Also some results concerning the failure mechanism are presented and compared with the ones obtained from classical solid mechanics simulations. One of the difficulties associated to the numerical analysis of the vane test is dealing with large deformations and the strain localized zone produced in the failure area. Even some of the large-strain finite element models have disadvantages when large local deformations are involved. The problems derived from the distortion of elements can be avoided if an Arbitrary Lagrangian-Eulerian formulation (ALE) coupled to the Finite Element Method (FEM) is used. In a Lagrangian formulation mesh points coincide with material particles. Each element contains always the same amount of material and no convective effects are generated. In this case the resulting expressions are simple, but it is difficult to deal with large deformations. On the other hand, a Eulerian formulation considers the mesh as fixed and the particles just move through it. Now convective effects appear due to the relative movement between the grid and the particles, but it is possible to simulate large distortions. An ALE formulation reduces the drawbacks of the purely Lagrangian or Eulerian formulations, and it is appropriate when large deformations are expected. For this reason the method was first proposed for fluid problems with moving boundaries ${ }^{19,20}$ and has been used in this paper to analyse the vane test. Following that approach, the material involved in the vane test has been simulated as a plastic incompressible 
fluid. That would take into account the large strains involved in the test. Also, the rate of rotation may be easily considered as velocities instead of displacements are the main variables. The fact that the vane test is more appropriate for very soft materials makes reasonable the analysis using a constitutive law for a plastic fluid. Applications of ALE to Geomechanics using classical elastoplastic constitutive laws for solids have been published elsewhere. ${ }^{21-23}$

In the next section, the main characteristics of vane test are outlined, pointing out some of the drawbacks of the test that complicate its interpretation. Then a basic description of the theoretical constitutive laws used in this paper is presented. Also the equations involved in the problem, taking into account the ALE formulation, are shown. A dimensionless formulation allows the definition of some combination of parameters that control the mathematical problem. These dimensionless numbers can explain the variability of vane results reported in some previous works. Then some applications to theoretical fluids and to real materials (soft clay and slurry red mud) are presented. These examples show a close dependency between amplitude of the strain localized zone, type of failure during the test, and constitutive models considered and are useful to clarify the interpretation of the vane test.

\section{MAIN FEATURES OF FIELD VANE TEST}

\section{There is a general agreement concerning the essential geometry of the vane. Figure 1 shows} the main elements of the equipment and its usual dimensions. ${ }^{2+}$ Although there are other
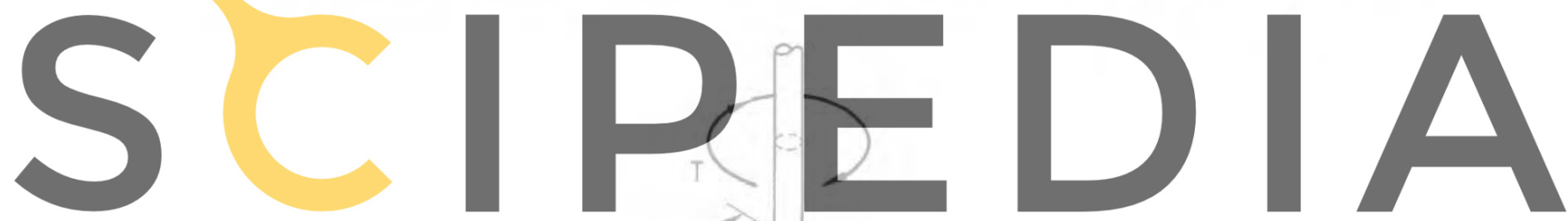

Register for free at https//www.scipedia.cem to download the version without the watermark

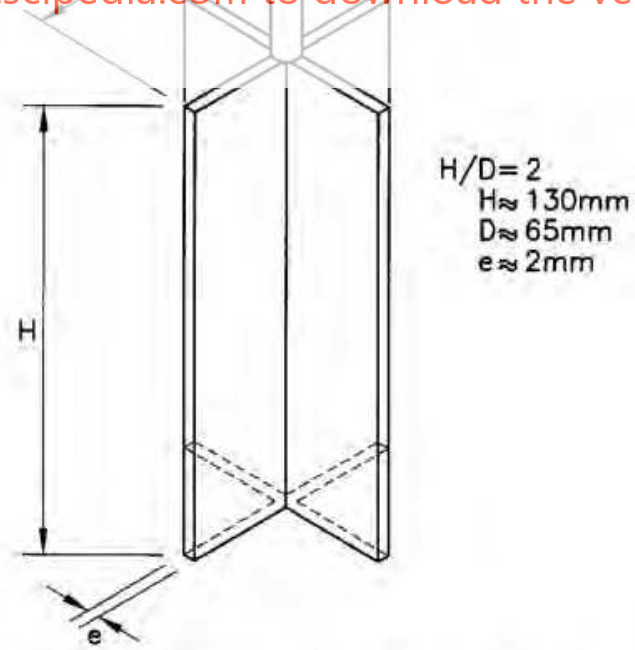

Figure 1. Typical dimensions of the field vane (after Chandler $^{24}$ ) 
configurations with different shapes and number of blades, ${ }^{26}$ the most popular one consists of four rectangular blades with a ratio $H / D$ of $2: 1$. The test is performed by rotating the central rod (usually by hand) and measuring the torque applied. This produces a cylindrical shear surface on the soil, and therefore the maximum torque measured is related to the undrained shear strength of the material, $s_{\mathrm{u}}$. Despite its simple use, the interpretation of the test is not always straightforward. A few shortcomings of the test have been reported during the past 30 years, mainly related to the stress distributions on the failure surfaces and to the influence of time on the results.

\section{Stress distributions}

The distribution of stresses around the failure surface is not always uniform, although the usual expressions presented in the codes of practice to compute $s_{\mathbf{u}}$ from the torque assume that uniformity. Two causes have been reported as main origin of non-uniformity: soil anisotrony and

progressive failure.

The total torque, $T$, is employed in creating a vertical cylindrical failure surface and, also, two horizontal failure surfaces in the top and the bottom of the material involved in the test. Thus $T=T_{\mathrm{v}}+T_{\mathrm{h}}$, where each term corresponds to the contribution of the torque from each failure surface. If the stress distribution is assumed constant in all surfaces then, by limit equilibrium, it is possible to evaluate

$$
T_{\mathrm{v}}=\frac{1}{2} \pi D^{2} H S_{\mathrm{u}} \text { and } T_{\mathrm{h}}=\frac{1}{6} \pi D^{3} S_{\mathrm{u}}
$$
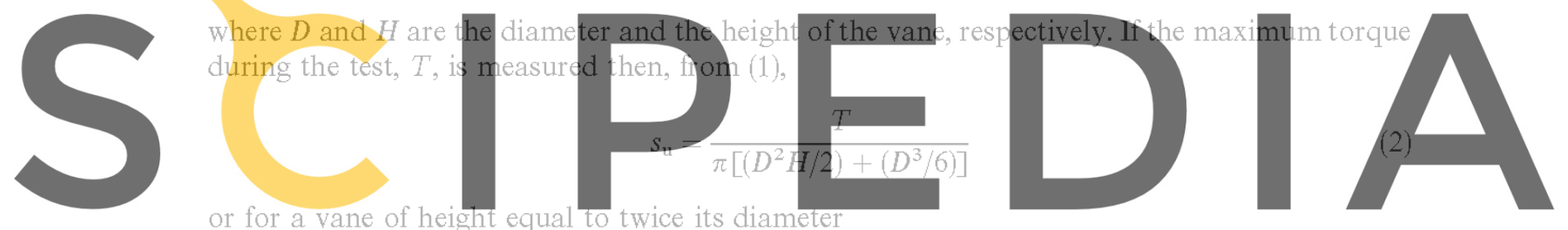

or for a vane of height equal to twice its diameter

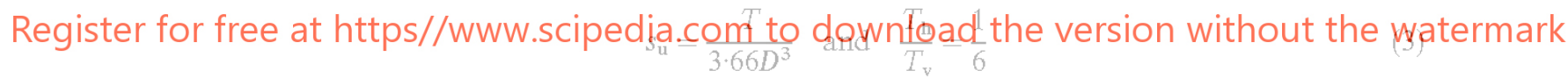

The stress distributions obtained from experiments or from numerical analyses are partiy different from the assumptions above considered. For instance, Figure 2 shows the stress distributions on the failure surfaces measured in the blades of an instrumented vane, ${ }^{6}$ and it may be seen that the distribution of shear stresses on the top is very different from the uniform assumption. Numerical results using an elastic constitutive law ${ }^{5}$ already suggested a nonlinear distribution of stresses in the top of the vane (Figure 3(a)). From these results, Wroth ${ }^{27}$ proposed a polynomial function to represent the shear stress distribution $\tau=\tau(r)$ at the top and bottom surfaces, and therefore

$$
\tau=s_{\mathrm{u}}\left(\frac{r}{D / 2}\right)^{n} \text { and } T_{\mathrm{h}}=\frac{\pi D^{3} s_{\mathrm{u}}}{2(n+3)}
$$

where $r$ is indicated in Figure 3(a). Worth suggested a value of $n=5$ for London clay, based on the results from Menzies and Merrifield. ${ }^{6}$ For this value, the torque ratio becomes smaller: $T_{\mathrm{h}} / T_{\mathrm{v}}=1 / 16$. Hence, the contribution of the horizontal failure surfaces to the total torque seems to be less significant in practice. That is, almost 94 per cent of the resistance to torque is provided by the vertical failure surface. As a consequence of that, classical expressions to obtain $s_{\mathrm{u}}$ would 
VANE TEST
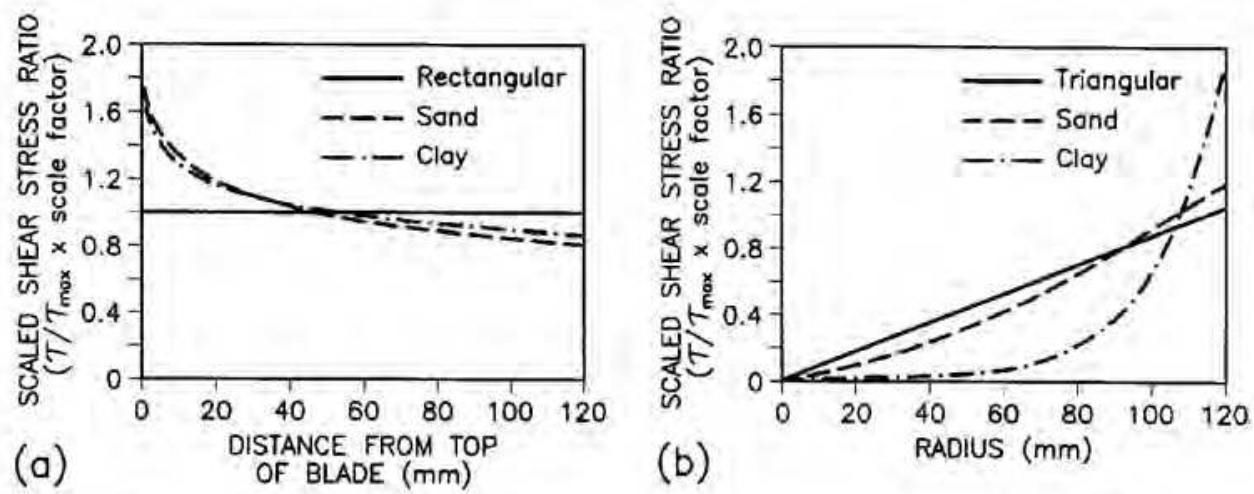

Figure 2. Measured stress distributions at vane blades (alter Menzies and Mernifield')

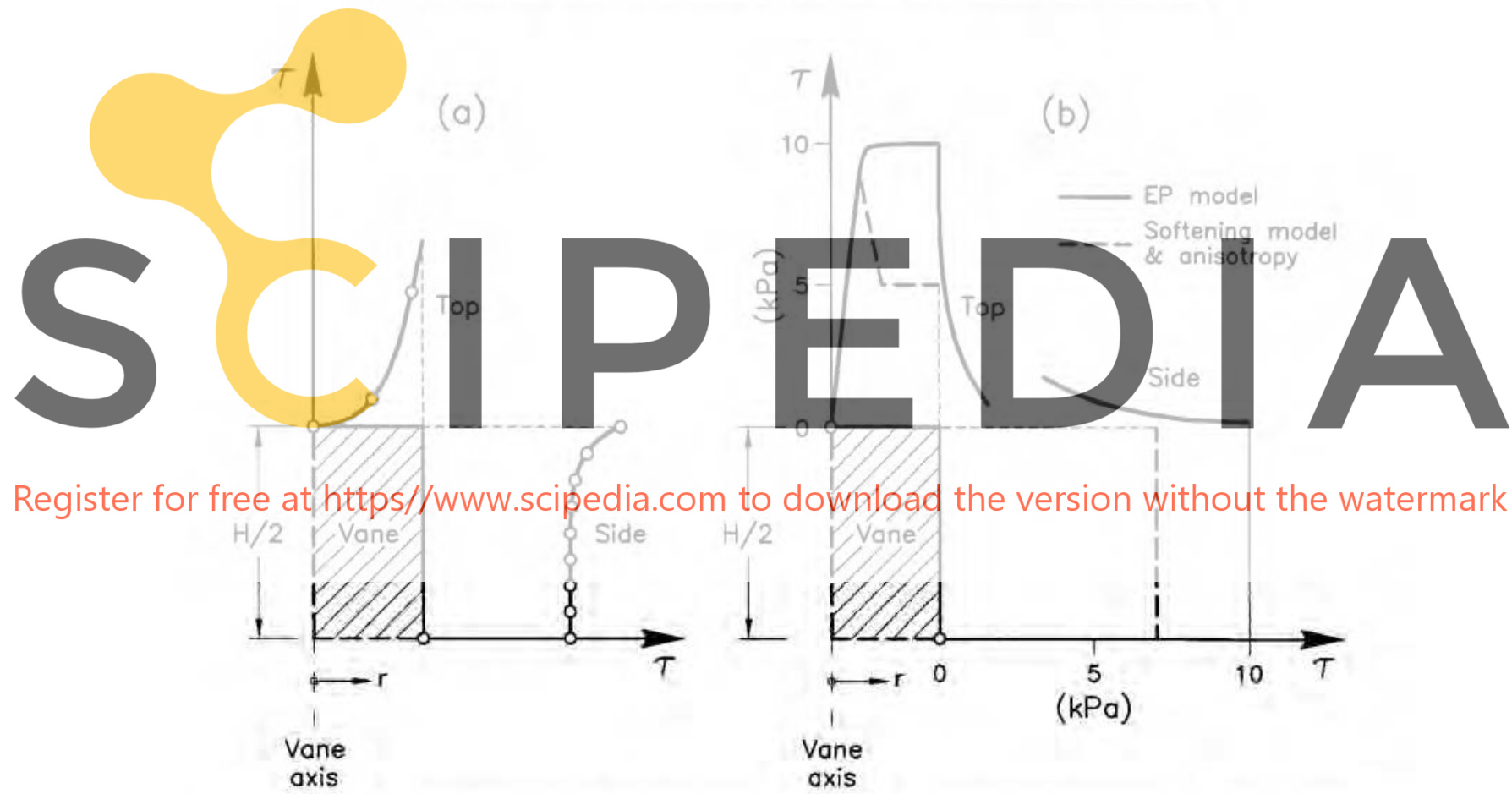

Figure 3. Shear stress distributions on sides and top of vane obtained from numerical simulations. (a) Elastic model (after Donald et $a l_{,}^{5}$ ). (b) Using an elastoplastic model and a st rain softening model including anisotropy (after Griffiths and Lane $^{10}$ )

underestimate the actual value of shear strength and that has been reported by some authors. ${ }^{27.28}$

Equation (4) is quite general as according to the value of $n$ different stress distributions for the top and bottom of the vane can be considered. From that results it seems that a value about $n=5$ could be appropriate. However, some authors have confirmed recently values close to $n=0$ for 
different soils, ${ }^{26}$ which corresponds again to a uniform stress distribution. A finite element analysis presented by Griffiths and Lane ${ }^{10}$ confirms that for elastoplastic materials the shear stress can be close to a constant value on the top of the vane (Figure 3(b)). They also showed an elastic analysis which is consistent with that presented by Donald et al. ${ }^{5}$ Therefore, the value of $n$ will depend on the stress state reached on the top and bottom of the vane, and that is difficult to predict in advance. This conclusion assumes that soil is isotropic, which is not always the case. When the soil is anisotropic, the interpretation of the test becomes more difficult, as, for instance, maximum shear stress can be reached in the vertical surface whereas the situation on the top is still elastic. As the result used from the test is the peak of the curve torque-rotated angle, which is in fact an integral of all these stresses, it is difficult to distinguish all these effects from just one measured value. As the vane includes vertical and horizontal failure surfaces, some attempts have been made to identify anisotropy by means of vanes with different dimensions and shapes in order to estimate $T_{\mathrm{h}}$ and $T_{\mathrm{V}}$ separately. ${ }^{5,29,30}$ Bierrum $^{11}$ proposed a correction factor to account for the anisotropy that has been critiziced in some cases. ${ }^{15,31}$

When the soil is isotropic and is not strain softening, as the maximum shear strains are produced at $r=R_{\mathrm{v}}$, where $R_{\mathrm{v}}$ is the vane radius, it is expected to reach the maximum shear stress at the vertical surface failure. If this value is kept constant, then plastification of the top and bottom vane will occur and the peak measured torque will correspond to a uniform distribution of shear stresses in all surfaces. However, if the soil has a strain softening constitutive law, the shear stress on the vertical failure will decrease and the peak torque will correspond to an

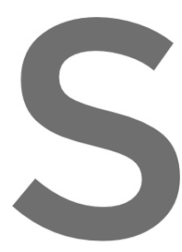
intermediate situation and $n>0$. Moreover, when strain softening occuls, the shear stress is not constant, which mal consistent with the simulated the vane peak shear strength employed. Numeric same dependence AIt those results showed the interpretation of the test.

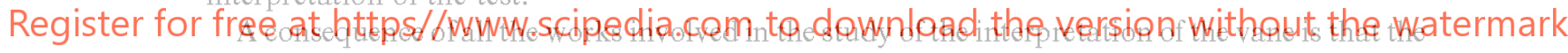
complete stress-strain curve of the material and its anisotropy must be known in advance in order to explain correctly the results of the test. However, for isotropic soft materials it seems to be an appropriate test, and the vertical failure surface would be predominant in that case.

\section{Time effects}

The influence of time on the results of the test has two different aspects: the delay between insertion and rotation of vane, and the rate of vane rotation. The disturbance originated by the vane insertion and the consolidation following that insertion are difficult to predict in general. There are a few experimental studies about these effects. They suggest that in order to reduce the vane insertion effects, blade thickness related to vane size must be as small as possible. ${ }^{32,33}$ On the other hand, the delay on carrying out the test after vane insertion increases the measured shear strength, due to the dissipation of pore water pressures originated by the insertion and also due to thixotropic effects. This effect is usually not considered in vane analyses, but there is experimental evidence on the high pore pressure developed by vane insertion ${ }^{8}$ and on the microstructural changes due to thixotropic phenomena. ${ }^{34}$ Results from Torstensson ${ }^{33}$ show that within 5 min after insertion measured shear strength does not change. It must be pointed out that 
both effects depend on the type of clay involved in the test (sensitivity, consolidation coefficient $c_{\mathrm{v}}$, etc.). Fabric disturbance due to insertion reduces the true undrained strength in about 10 per cent, but if consolidation after insertion is permitted a 20 per cent increase on strength is produced. ${ }^{24}$ The standard vane test is usually performed $1 \mathrm{~min}$ after the insertion of the blades, which is the maximum delay value suggested by Roy and Leblanc. ${ }^{25}$ In that case, no consolidation is allowed.

The effect of the rate of vane rotation on the interpretation of the test is also important. The standard rate is $6-12 \% \mathrm{~min}$. That produces failure in about $30-60 \mathrm{~s}$, a shorter time than in classical triaxial tests or shear tests. Due to this difference, undrained strengths from vane tests are overestimated if compared with that obtained from classical laboratory tests. This effect can be compensated with the underestimation of $s_{u}$ provided by other eflects (fabric disturbance, stress uniformity, ...), but their magnitude is difficult to estimate. As the vane is an undrained test, some recommendations regarding a minimum angular velocity are defined in the codes of practice. Assuming a time to failure of one minute, undrained conditions can be assured if the consolidation coeflicient of the material is: $c_{\mathrm{v}} \leqslant 3.5 \times 10^{-2} \mathrm{~cm}^{2} / \mathrm{s}$, which is usually the case when soft clays are tested. However, as in other undrained tests, measured strength increases with the velocity of the load application and this effect leads to difficulties in the interpretation of results. To consider that, Bjerrum ${ }^{11}$ proposed a reduction of the shear strength measured with the vane aecording to the plasticity index of the clay, as the usual values of shear strength obtained in the laboratory correspond to slower experiments than field vane. Measurements of vane shear strength for different velocities of rotation have been published by Wiesel ${ }^{30}$ and Torstensson. ${ }^{33}$

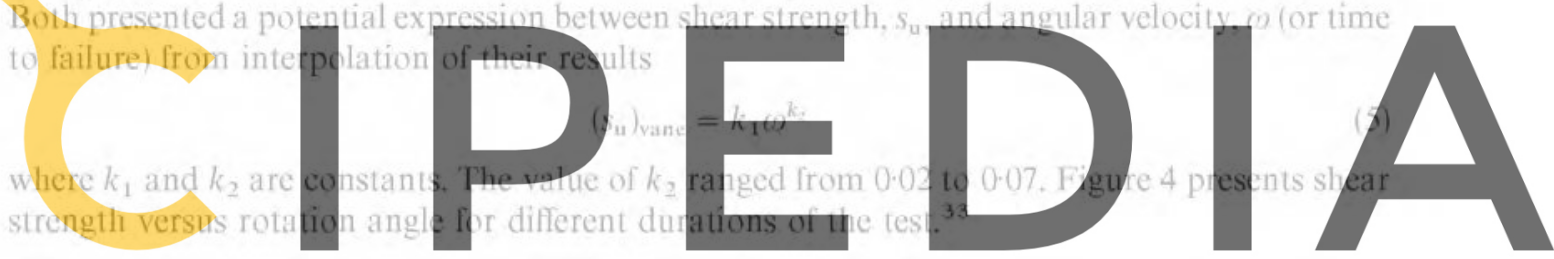

Register for free at ĥttps//www.scipedia.com to download the versignwithout the watermark

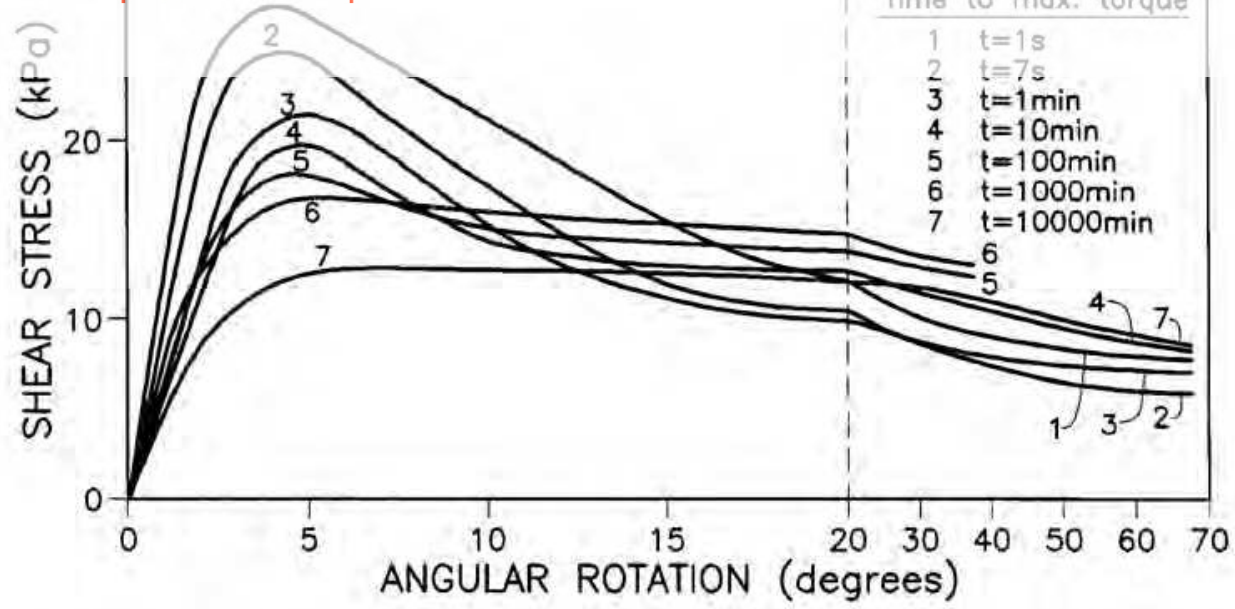

Figure 4. Shear stress-angular rotation obtained using different testing rates on Bäckebol clay, Sweden (after Torstensson ${ }^{25}$ ) 
The comparison of results from vanes of different shapes and different strain rates has been difficult as these effects are only related to the shear strength on the basis of empirical relations which may depend on the soil considered. A reference shear velocity: $v=\omega R_{\mathrm{v}}$ as a variable to compare results from different vanes was proposed by Perlow and Richards. ${ }^{35}$ They obtained an almost linear relationship between vane shear strength and shear velocity $v$ for two marine sediments, but they did not have enough experimental data to propose a definite relationship. In fact, some results reported by other authors, ${ }^{15}$ show no influence of the vane radius on the measured shear strength. These differences may be due to side effects as sampling disturbance or stress relief for soils used in laboratory vane tests, which would reduce the apparent shear strength. ${ }^{16}$ However, in general, that is taken into account when estimating $s_{\mathrm{u}}$. This is still a controversial issue, and it will be considered later using the formulation presented in following sections.

The shortcomings presented have been extensively studied by many authors, but still there are contradictions on results and on interpretations of vane measurements. This is due to the fact that vane test is a model test rather than an element test. ${ }^{17}$ Apart from that, other effects on vane strength have been rearely studied: for instance, influence of the stress state and $K_{0}$ (coefficient of lateral earth pressure at rest) on the result. ${ }^{31,36}$ As a consequence of the drawbacks above mentioned, the vane test seems indicated for very soft isotropic materials. Also the dominant failure surface is the vertical one. Therefore, it is reasonable to perform numerical simulations by means of two-dimensional analyses, in order to study rate effects and stress distributions. Hence, the use of plastic fluid constitutive laws and fluid mechanics equations may be appropriate to

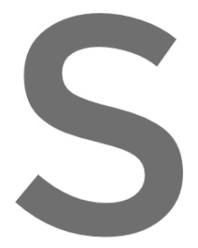
analyse time effects insertion and the 3 D
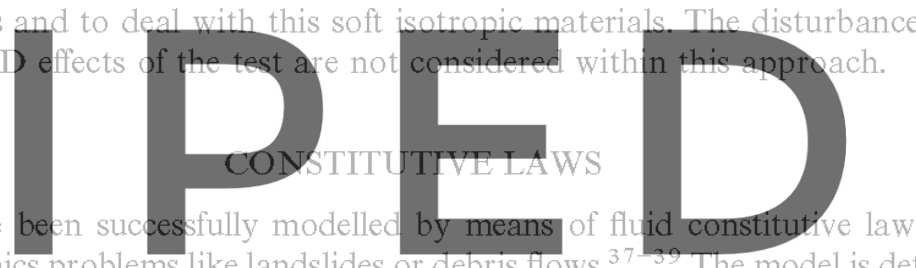

of a shear stress-shear strain rate relationship, instead of a stress-strain one. The study of strain rate

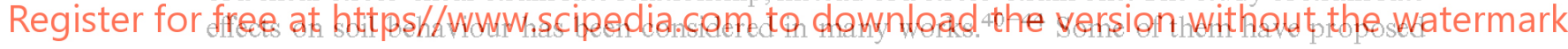
constitutive laws relating stresses with strains and strain rates to account for time influence, based on a visco-elasto-plastic theory. Bjerrum ${ }^{11}$ indicates that time effects in soft clays are associated with the cohesive component of the shear strength which is of a viscous nature; the frictional component of the shear strength would be further mobilized. Therefore, it is not absurd to study the vane test assuming that the material involved is a plastic fluid, particularly at the beginning of the test, when viscous effects are definite. These effects depend on the type of clay considered, and plasticity index has been used historically to distinguish between different behaviours of normally consolidated clays. However, Tavenas and Lerouei ${ }^{45}$ propose to use the limit liquid instead, because it requires only a single test and in fact the resulting correlations are essentially the same.

Let us assume that the clay involved in the test is saturated and normally consolidated. When viscous effects are studied in detail, it is found that for a particular soil (that is for a particular liquid limit $w_{\ell}$ ), the soil behaviour depends on the water content $w$, as shown in Figure 5, from Komamura and Huang. ${ }^{41}$ According to them, when $w>w_{\ell}$ the behaviour is viscous, that is, close to a Newtonian fluid; whereas when $w<w_{\mathrm{vp}}$ the behaviour is visco-elasto-plastic. The value $w_{\mathrm{vp}}$ was defined as viscoplastic limit, between plastic and liquid limits.

Results obtained in a torsional hollow cylinder are reproduced in Figure 6, from Cheng. ${ }^{42}$ The material was a Mississippi Buckshot clay with a water content close to its plastic limit. It 
VANE TEST
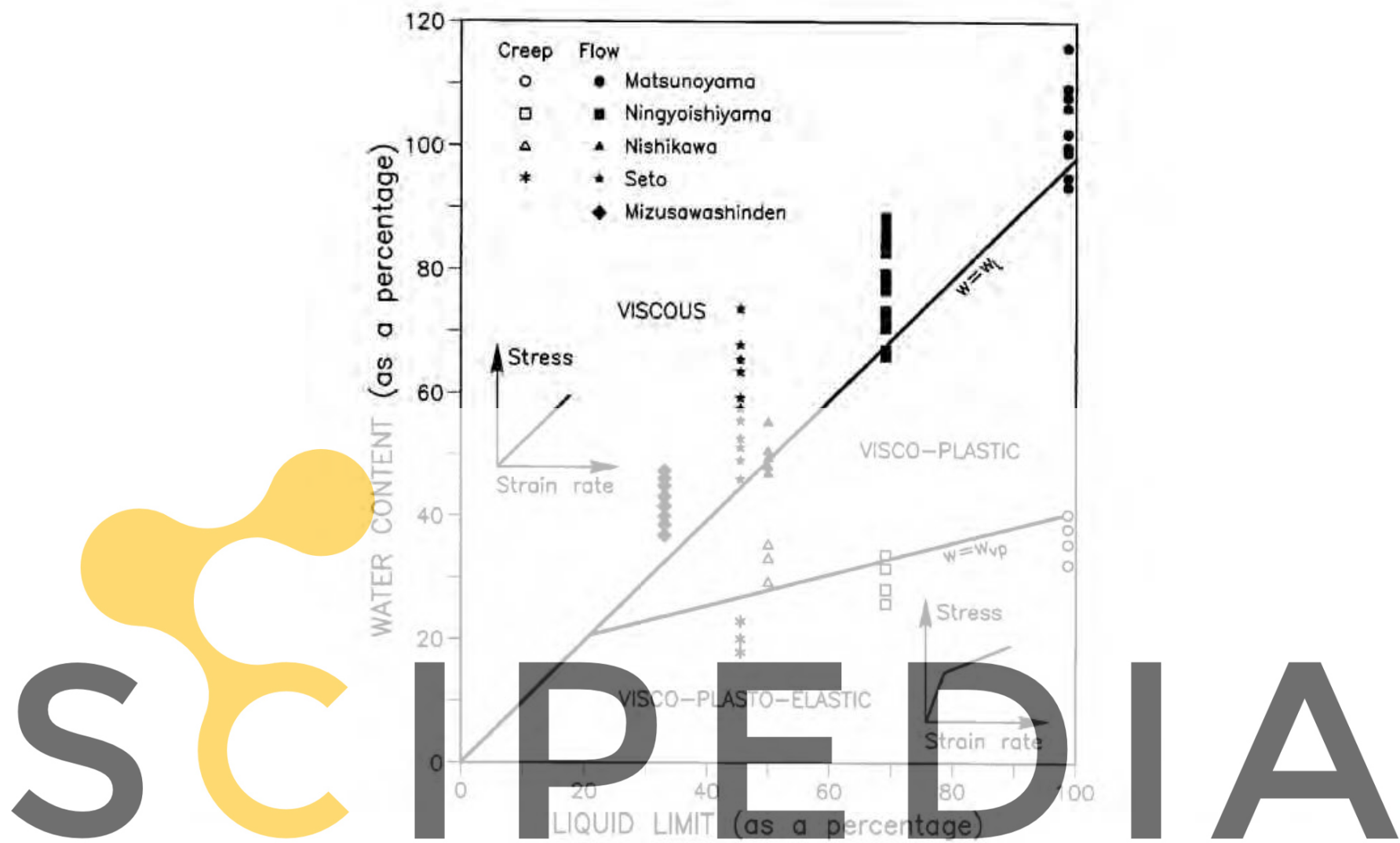

Figure 5. Rheological state of sol in accordance with water content for some Japanese. clays (after Komamura and Register for free at https//www.scipedia.com to download the version without the watermark

ma be seen that its behaviour is consistent with the trends established by Komamura and Huang. ${ }^{41}$ However, further works have shown that some clays may have a visco-elasto-plastic behaviour with water content above their liquid limit. ${ }^{46-48}$ Curves obtained by Locat and Demers $^{48}$ using a viscosimeter device are presented in Figure 7 . Note, nevertheless, that the shear rate range is different for the results reproduced in Figure 6 and for those indicated in Figure 7. Some consequences of this difference will be treated later. The works indicated show that fluid constitutive laws for modelling the soil behaviour have been successfully employed to account for the time effects which are supposed to be important when water content is high, but it is difficult to establish a particular behaviour for each soil state in advance.

The general constitutive equation to be used in this work is a general relationship between stresses and strain rates:

$$
\sigma_{i j}=f\left(d_{i j}\right)
$$

where $\sigma_{i j}$ is Cauchy's stress tensor and the strain rate tensor is defined as

$$
d_{i j}=\frac{1}{2}\left(\frac{\partial v_{i}}{\partial x_{j}}+\frac{\partial v_{j}}{\partial x_{i}}\right)
$$




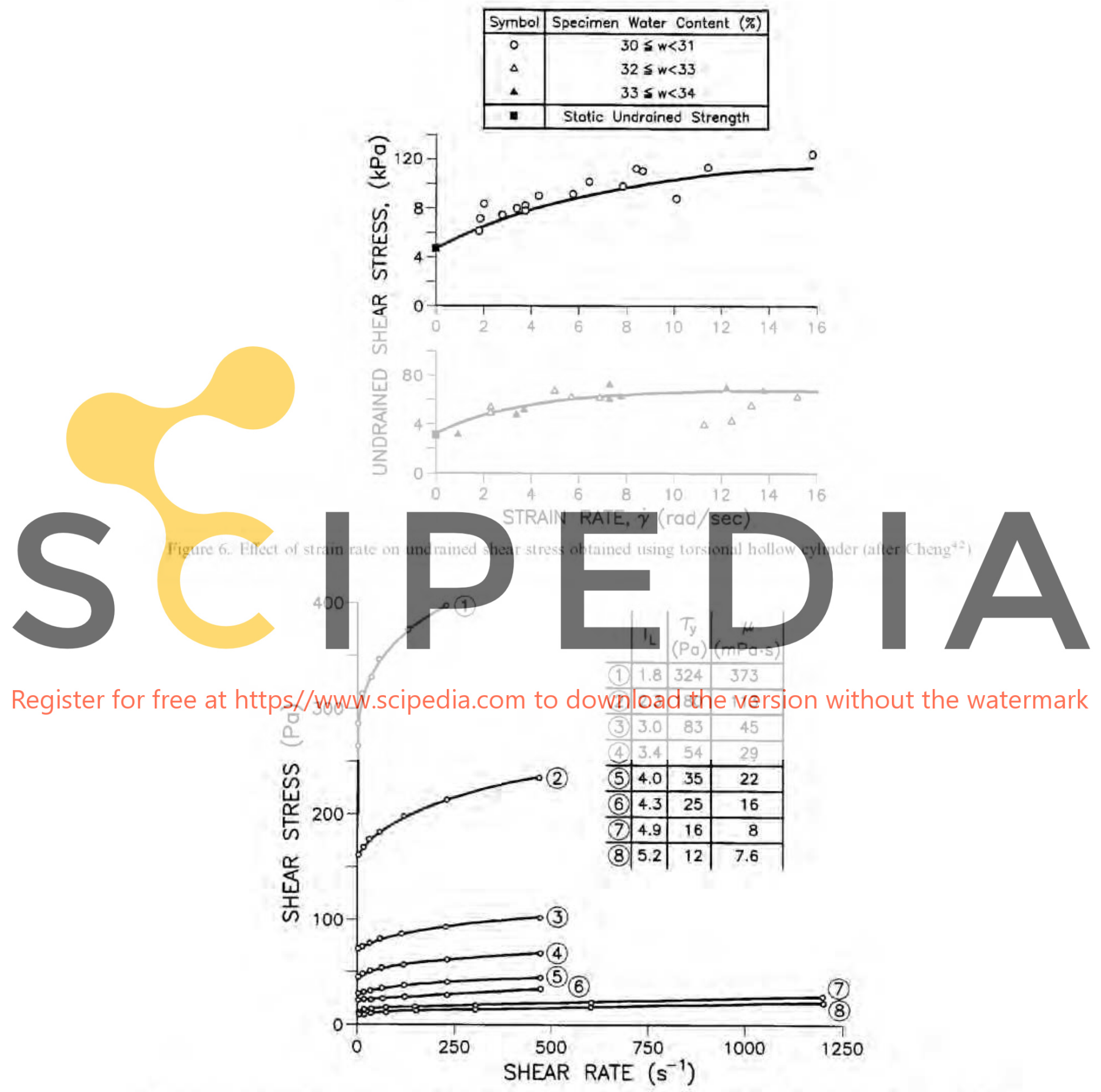

Figure 7. Shear stress-shear st rain rate obtained from viscosimeter experiments with St. Alban-1 marine clay with a salt content of $02 \mathrm{~g} / 1 ; \tau_{\mathrm{y}}$ is yield stress, $I_{\mathrm{L}}$ is liquidity index and $\mu$ is viscosity (after Locat and Demers ${ }^{48}$ ) 
where $x_{i}$ and $v_{i}$ are position and velocity vectors respectively. A common expression for equation (6) is

$$
\sigma_{i j}=-p \delta_{i j}+2 \mu d_{i j}
$$

where $p$ is the hydrostatic pressure (tension positive) and $\mu$ is the dynamic viscosity. Equation (8) can be rewritten as

$$
\sigma_{i j}^{\mathrm{d}}=2 \mu d_{i j}
$$

where $\sigma_{i j}^{\mathrm{d}}$ is the deviatoric stress tensor. When viscosity is assumed constant, the fluid is called Newtonian. A generalized Newtonian fluid is defined by a viscosity which depends on the strain rate tensor. Also, some plastic fluids show a 'yield stress', that is, below that value no flow is observed, which is equivalent to an infinite viscosity in terms of equation (9). However, some authors $^{49}$ indicate that the yield stress does not exist, provided that accurate measurements are performed. That is, 'yield stress' is just an idealization of the actual behaviour.

Table I shows a list of constitutive laws available for fluids. ${ }^{20}$ From that list, the models by Binghm, Casson and Herschel and Bulkley seem to be most appropriate for soft materials. Those

Table I. Some generallized Newtonian fluid models defined in terms of viscosity. $\tau=\sqrt{\sigma_{i j}^{d} \sigma_{i j}^{d} / 2}$ and $\hat{\gamma}=\sqrt{2 d_{i j} d_{i j}}$. (After Huerta and $\left.\mathrm{Liu}^{20}\right)$. A simplified $1 \mathrm{D}$ representation of the models is included

Newtonian

Carreau

Bingham

Herschel-Bulkley

Casson

$$
\mu=\mu_{0}
$$

Carreau
\[ \begin{array}{l}\mu=\left(\mu_{0}-\mu_{\mathrm{oc}}\right)\left(1+(\lambda \dot{\gamma})^{2}\right)^{(\mu-1) / z}+ \\ \mu=\infty \text { if } \tau \leqslant \tau_{0} \\ \mu=\mu_{p}+\tau_{0} / \gamma \text { if } \tau>\tau_{0}\end{array} \]
Bingham
\[ \begin{array}{l}\mu=\infty \text { if } \tau \leqslant \tau_{0} \\ \sqrt{\mu}=\sqrt{\mu_{p}}+\sqrt{\tau_{0} / \gamma} \text { if } \tau>\tau_{0}\end{array} \]
$\begin{aligned} & \mu=\infty \text { if } \tau \leqslant \tau_{0} \\ & \sqrt{\mu}=\sqrt{\mu_{p}}+\sqrt{\tau_{0} / \gamma} \text { if } \tau>\tau_{0}\end{aligned}$
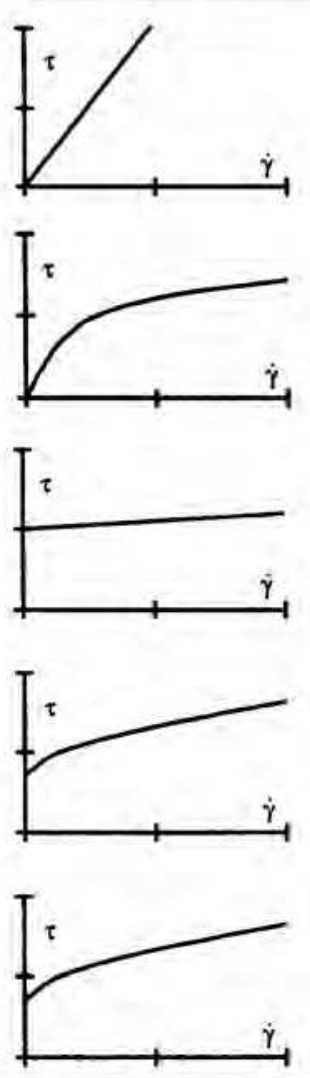
models simulate a 'yield stress' value up to which no velocities or displacements occur. According to the yield stress magnitude, it is possible to reproduce effects observed in the actual behaviour of soft materials. For instance, the amplitude of the strain localized zone, the influence of the progressive failure or the brittleness of the material are supposed to be determined by the constitutive law used and specially by the existence of the 'yield stress'. The fluid models indicated above are consistent with experimental results like the ones depicted in Figures 6 and 7, and they will be used as constitutive laws in this simulation. However, any relation between stresses and strain rates could be implemented in the formulation.

\section{BASIC EQUATIONS AND ALE FORMULATION}

\section{Basic equations}

Fluid movement is described by two basic equations: mass conservation equation and equilibrium equation. These equations are, respectively,

$$
\begin{gathered}
\frac{\partial \rho}{\partial t}+\rho \frac{\partial v_{i}}{\partial x_{i}}=0 \quad \text { in } \Omega \\
\rho \frac{\partial v_{i}}{\partial t}+\rho c_{j} \frac{\partial v_{i}}{\partial x_{j}}=\rho b_{i}+\frac{\partial \sigma_{j i}}{\partial x_{j}} \quad \text { in } \Omega
\end{gathered}
$$

where $\rho$ is the density of the material, $t$ is the time, $c_{j}=\hat{v}_{j}-v_{j}$ with $\hat{v}_{j}$ being the velocity of the reference system, $b_{i}$ is the mass forces vector and $\Omega$ is the domain of study. Also, repeated index means summation.

As incompressible flow is assumed, density is constant and expression (14a) leads to div $v=0$ which is equivalent to the undrained condition assumed in the standard field vane test. Introducing this result and the constitutive law presented above in (14b) gives

$$
\rho \frac{\partial v_{i}}{\partial t}+\rho c_{j} \frac{\partial v_{i}}{\partial x_{j}}=\rho b_{i}-\frac{\partial p}{\partial x_{i}}+\frac{\partial}{\partial x_{j}}\left(\mu[\dot{\gamma}]\left(\frac{\partial v_{i}}{\partial x_{j}}+\frac{\partial v_{j}}{\partial x_{i}}\right)\right) \text { in } \Omega
$$

where $\mu[\dot{\gamma}]$ is the dynamic viscosity, function of the shear strain rate, $\dot{\gamma}=\sqrt{2 d_{i j} d_{i j}}$.

The boundary conditions applied are $v_{x}=v_{y}=0$ at the outer boundary and $v_{x}=$ $\omega r \sin \left(\theta_{0}+\omega t\right)$ and $v_{y}=-\omega r \cos \left(\theta_{0}+\omega t\right)$ at the blade contours, with $\omega$ the angular velocity of the vane and $\left(r, \theta_{\mathrm{o}}\right)$ the polar coordinates of the blade nodes at $t=0$. The initial stresses and velocities are considered zero in all the points and in the boundaries.

In order to find out the parameters that govern the problem, a set of dimensionless variables

$$
\bar{x}=x / R^{*}, \quad \bar{p}=p / \tau^{*}, \quad \bar{v}=v / R^{*} \omega^{*} \quad \text { and } \quad \bar{t}=t \omega^{*}
$$

is substituted in equation (15), where $R^{*}, \tau^{*}, \omega^{*}$ are characteristic length, stress and angular velocity of the test, respectively. Usually, the vane radius, $R_{v}$, is adopted for $R^{*}$, the angular velocity of the test for $\omega^{*}$, and the material yield stress for $\tau^{*}$. Then equation (15) is transformed into a dimensionless expression:

$$
\frac{1}{N e}\left(\frac{\partial \bar{v}_{i}}{\partial t}+\bar{c}_{j} \frac{\partial \bar{v}_{i}}{\partial x_{j}}\right)=-\frac{\partial \bar{p}_{i}}{\partial x_{i}}+\frac{\partial}{\partial \bar{x}_{j}}\left(\frac{1}{N e R e}[\dot{\gamma}]\left(\frac{\partial \bar{v}_{i}}{\partial \bar{x}_{j}}+\frac{\partial \bar{v}_{j}}{\partial x_{i}}\right)\right) \text { in } \Omega
$$




\section{VANE TEST}

Table II. Numerical values of $N_{1}$ and $N_{2}$ for different materials, vane sizes nd angular velocities

\begin{tabular}{ccccccc}
\hline & $\begin{array}{c}\rho \\
\left(\mathrm{kg} / \mathrm{m}^{3}\right)\end{array}$ & $\begin{array}{c}R^{*} \\
(\mathrm{~m})\end{array}$ & $\begin{array}{c}\tau^{*} \\
(\mathrm{~Pa})\end{array}$ & $\begin{array}{c}\omega^{*} \\
\left(\mathrm{~s}^{-1}\right)\end{array}$ & $N_{1}$ & $\min \left(N_{2}\right)$ \\
\hline Red mud & 1200 & 0.013 & 126 & $0 \cdot 01$ & $1 \cdot 6 \mathrm{E}-7$ & $2 \cdot \mathrm{E}-2$ \\
& 1200 & 0.013 & 126 & $0 \cdot 21$ & $7 \cdot 1 \mathrm{E}-5$ & $2 \cdot \mathrm{E}-2$ \\
\multirow{5}{*}{ Soft clay } & 1400 & 0.0325 & 2000 & $0 \cdot 0017$ & $2 \cdot 1 \mathrm{E}-9$ & $4 \cdot \mathrm{E}-2$ \\
& 1400 & 0.0325 & 2000 & $0 \cdot 0035$ & $9 \cdot 1 \mathrm{E}-9$ & $4 \cdot \mathrm{E}-2$ \\
& 1400 & 0.0325 & 2000 & $0 \cdot 0070$ & $3 \cdot 6 \mathrm{E}-8$ & $4 \cdot \mathrm{E}-2$ \\
\hline
\end{tabular}

with $R e$ and $N e$ equal to Reynolds and Newton number. The Reynolds number is related to viscous forces and the Newton one to inertial forces. They are defined as

$$
N e=\frac{\tau^{*}}{\rho\left(R^{*} \omega^{*}\right)^{2}} \quad \text { and } \quad R e=\frac{\rho \omega^{*}\left(R^{*}\right)^{2}}{\mu}
$$

The influence of $R e$ and $N e$ in equation (17) is in the form of

$$
N_{1}=\frac{1}{N e}=\rho \frac{\left(R^{*} \omega^{*}\right)^{2}}{\tau^{*}} \text { and } N_{2}[\dot{\gamma}]=\frac{1}{N e \operatorname{Re}}[\dot{\gamma}]=\mu[\dot{\gamma}] \frac{\omega^{*}}{\tau^{*}}
$$

and their characteristic values for some typical vane tests are shown in Table II. As $N_{1}$ is much less than $N_{2}$ and accelerations usually are not large enough to compensate this difference, the inertial terms can be neglected and the problem becomes quasi-static. In these cases the problem depends just on $N_{2}$, and therefore the test will be independent of the vane radius or the fluid density. The use of those dimensionless numbers may be useful when comparing different vanes, and they will be considered later to account for size and time effects.

\section{Computational aspects}

The finite element mesh employed in the analyses is shown in Figure 8. The mesh has 1492 elements and 1576 nodes, it is composed of 4 node-elements and increases the density of elements in the expected failure zone. Note that elements inside the vane failure circle have basically a rigid solid movement so a coarse mesh can be adopted there. Plane strain conditions were adopted in the simulations.

An ALE description was used for the resolution of the problem. ALE formulation has been employed to avoid the disadvantages of pure Eulerian or pure Lagrangian descriptions. If an Eulerian description is used, the mesh is fixed. That is easy to formulate, but makes difficult imposing the boundary conditions at the vane blades. On the other hand if Lagrangian description is adopted, the nodes will follow the particle movements and mesh distortions will arise. ALE formulation can be interpreted as combination of both descriptions: the mesh is rotated at the same velocity as the vane blades, so the soil particles have an Eulerian description; whereas the boundary is defined in Lagrangian terms, as the mesh follows the boundaries during the test. Therefore, the velocities of any node of the mesh are

$$
\hat{v}_{x}=\omega r \sin \left(\theta_{0}+\omega t\right) \text { and } \hat{v}_{y}=-\omega r \cos \left(\theta_{\mathrm{o}}+\omega t\right)
$$




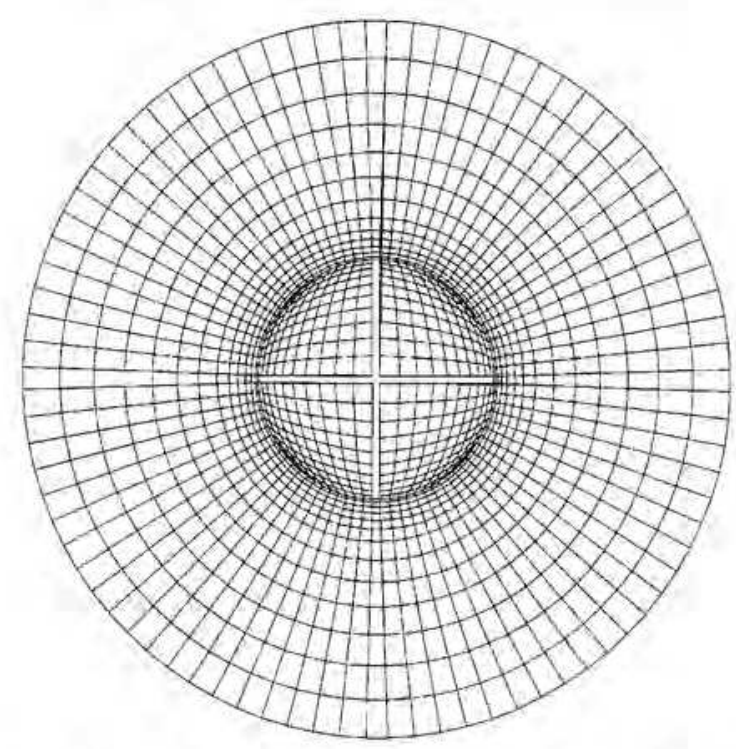

Figure 8. Finite element mesh used in the analyses, with a dimensionless vane radius of 1

where the symbol ^ stands for mesh prescriptions. Mesh displacements are found by integrating mesh velocities.

As a predictor-corrector algorithm is used in the numerical formulation, unknowns for time $t$ are computed from values at time $t-\Delta t$ simulating the transient problem. Similarly to ny transient problem starting from rest, boundary conditions (in this case the angular velocity of the blade) can not be discontinuous, i.e. a finite jump from zero to an imposed angular velocity which would induce an unphysical infinite angular acceleration. Therefore, a smooth variation of the angular velocity has been used. Thus, angular acceleration is always finite and becomes zero after a few time increments. As the problem is quasi-static, the acceleration is not important for the final torque, which depends mainly on the steady state value of the angular velocity reached.

As the simulation is performed by applying an angular velocity, the torque must be computed as a result of the analysis. One possibility is to estimate the torque from pressures acting on the vane blades, but in a mixed pressure-velocity formulation, the accuracy for the pressure is one order lower than the velocity. Thus, it is preferable to use an approach based on the evaluation of the power input, as the FEM is an energy based formulation. The power input, $P_{\text {inpur }}$, is the sum of two domain integrals; the first is the material time derivative of the kinetic energy of the system. while the second takes into account the variation of the internal energy:

$$
P_{\text {input }}=\frac{\mathrm{d}}{\mathrm{d} t} \int_{\Omega} \frac{1}{2} \rho v_{i} v_{i} \mathrm{~d} \Omega+\int_{\Omega} \sigma_{i j} d_{i j} \mathrm{~d} \Omega
$$

The first term can be neglected because the vane test is quasi-static and the second one is obtained by summation of the element contributions:

$$
P_{\text {input }}=T \omega \approx \sum_{i=1}^{\text {NuMtL }} \tau_{i} \dot{\gamma}_{i} S_{i}
$$


where NUMEL is the number of elements and $S_{i}$ the corresponding area for each element of the mesh. Note that in (22) only shear strain rates are used, as the problem has been considered incompressible. Finally, the torque applied, $T$, is directly obtained from that expression.

\section{ANALYSIS USING THEORETICAL CONSTITUTIVE LAWS}

Simulations using dimensionless Bingham and Carreau models are presented in order to analyze the influence of 'yield stress' in strain rate distribution. The four dimensionless constitutive laws depicted in Figure 9 have been considered. These models are similar within the range considered. However, there are two main differences between them: models 1 have mainly a horizontal relation between shear stress and shear strain rate and models 2 do not, and Bingham models have a well defined "yield stress", whereas Carreau models do not. The distribution of shear strain rates and shear stresses obtained in the simulations are represented in Figure 10 (Bingham 1. Bingham 2 and Carreau 2). The shear strain rate and the particle velocity distribution over a line at $45^{\circ}$ between blades, are depicted in Figure 11. The torque actually applied while performing the test is presented, in dimensionless form. in Figure 12. Also, Table III presents some numerical values corresponding to these examples.

Note that models 1 give almost the same results, and so do models 2 . The main difference between both is the more definite failure surface produced by models 1. Indeed. Figure 10(a) shows a well defined failure surface and close to a circle of unit radius. which corresponds to the vane radius in dimensionless form. Also the amplitude of the shear strain rate localization zone is very small, and the material between blades has almost a rigid solid movement, evident in Figure 11 where the velocity distribution in the material in a intermediate plane $\left(\theta=45^{\circ}\right)$ is almost $v=\omega r$, as in the blades. On the other hand models 2 have a wider shear strain rate localization zone, although it still could be considered a circular failure surface. It has been verified that models with a plateau in the $\tau$ vs. $\gamma$ constitutive law have a more definite and narrower localization zone. The differences between Bingham and Carreau models are similar but less important than between models 1 and models 2. Apart from that, Carreau models tend to

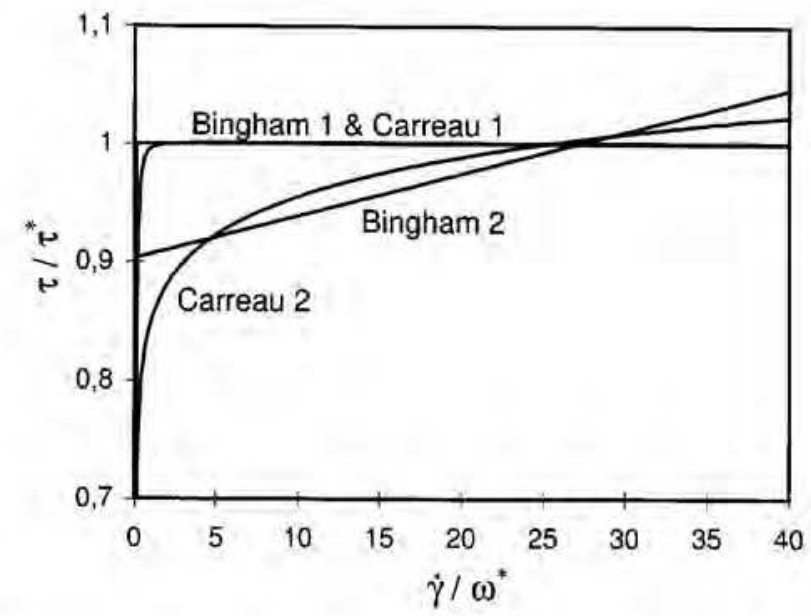

Figure 9. Dimensionless shear stress versus dimensionless shear strain rate for the theoretical constitutive laws 


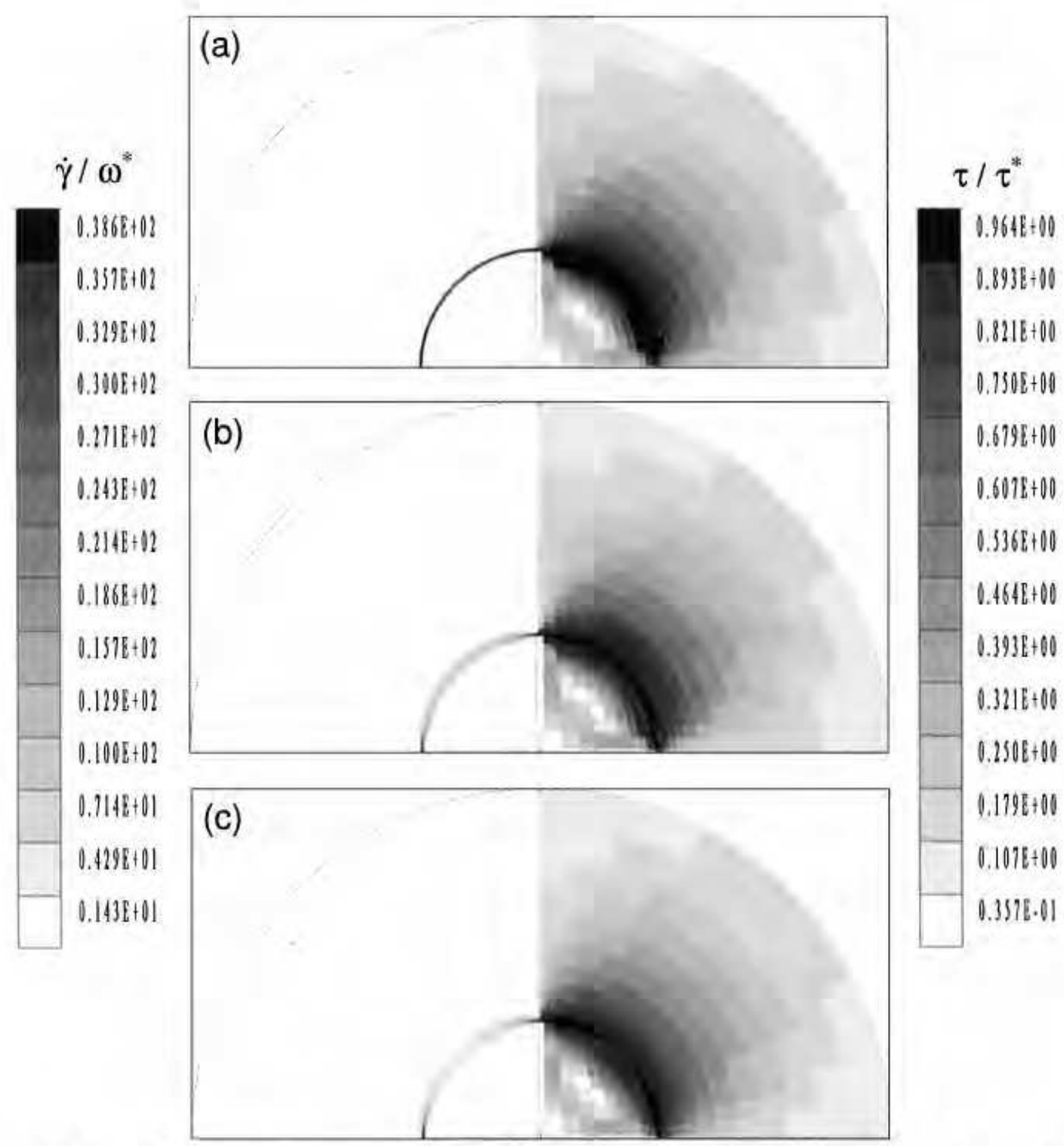

Figure 10. Shear strain rate and shear st ress distributions using the theoretical constitutive laws: Bingham 1; (a), Bingham 2 , (b) and Carreau 2 (c)

present a wider shear strain rate localization zone and less homogeneous distribution of velocities around failure surface than Bingham models.

It should be pointed out that the radius where the maximum shear stress is produced in a intermediate plane $\left(\theta=45^{\circ}\right)$ is almost the same in all the examples (Table III). At the blade planes, the maximum value of shear stress is obviously produced at $r=1$. Therefore the value 
VANE TEST

Table III. Numerical values of the analyses of the vane test using theoretical constitutive laws

\begin{tabular}{|c|c|c|c|c|}
\hline & Bingham 1 & Carreau 1 & Bingham 2 & Carreau 2 \\
\hline $\max _{\theta}=\sigma\left(t / R^{*} \omega^{*}\right)$ & 1.00 & 100 & 1.00 & 1.00 \\
\hline $\left.\max _{n}=45^{(}\left(v / R^{*} \omega\right)^{*}\right)$ & 0.95 & 0.91 & 0.91 & 0.78 \\
\hline$r / R^{*} \mid \max _{\theta=45}\left(v / R^{*} \omega^{*}\right)$ & 0.97 & 0.97 & 0.94 & 0.94 \\
\hline $\max _{\theta=0^{*}}\left(\gamma / \omega^{*}\right)$ & $39 \cdot 39$ & 38.74 & $37 \cdot 90$ & $35 \cdot 38$ \\
\hline $\max _{\theta=45}\left(\gamma^{\prime} / \omega^{*}\right)$ & $31 \cdot 25$ & 28.04 & 8.58 & $5 \cdot 53$ \\
\hline$r / R^{*} \mid \max _{\theta=45^{*}}\left(\hat{\gamma} / \omega^{*}\right)$ & 1.01 & $1 \cdot 01$ & 1.01 & $1 \cdot 00$ \\
\hline $\max _{i=0}\left(\tau / \tau^{*}\right)$ & 100 & $1-00$ & $1 \cdot 04$ & 1.02 \\
\hline $\max _{\theta=45^{\circ}}\left(\tau / \tau^{*}\right)$ & $1 \cdot 00$ & 1.00 & 0.93 & 0.93 \\
\hline$r R^{*} \mid \max _{\theta=45}\left(\tau / \tau^{*}\right)$ & $0.95-1.01$ & $1 \cdot 00-1.01$ & 1.01 & $1 \cdot 00$ \\
\hline$T / \tau^{*}\left(R^{*}\right)^{2}$ & 6.44 & $6 \cdot 44$ & $6-15$ & 6.11 \\
\hline
\end{tabular}
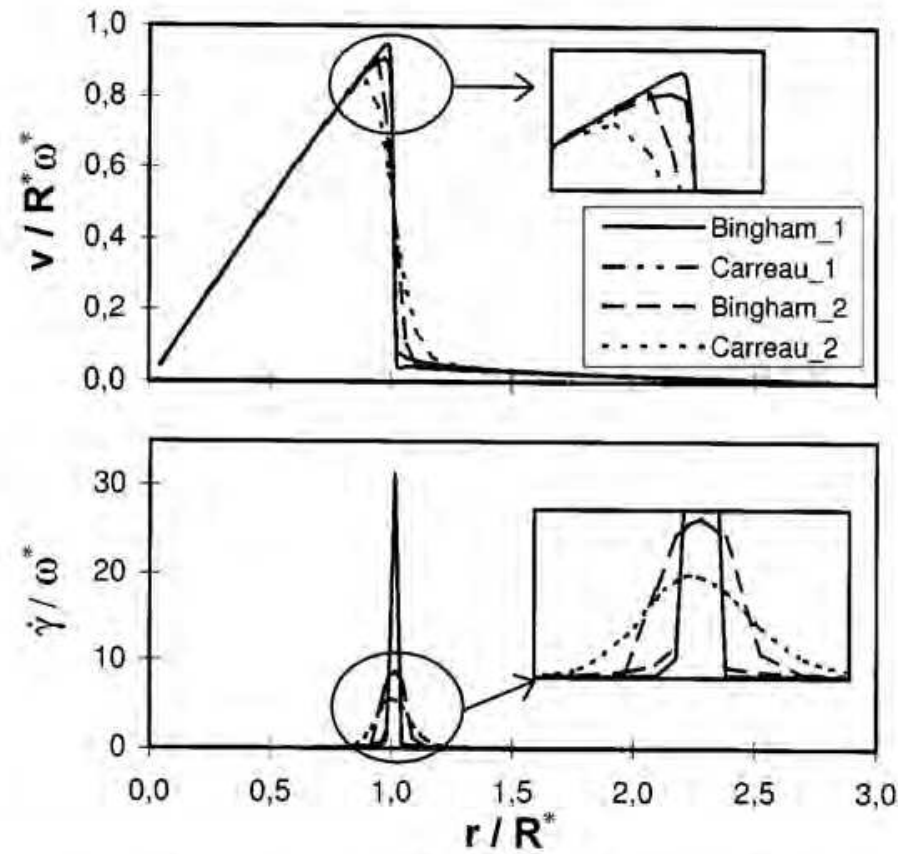

Figure 11. Dimensionless velocity and shear strain rate between blades using theoretical constitutive laws

adopted in classical formulations that consider the failure surface constant at $r=1$ seems reasonable. However some authors have reported failure surfaces at $r=1.05 R_{v}$ based on experimental observations (in Arvida clay-sensitive and overconsolidated), ${ }^{25}$ and even higher values (but in fibrous peat whose fibers extend the failure zone). ${ }^{50}$ That should be dependent on the material involved in the test so the result obtained in this simulation could only apply for soft clays. On the other hand, the shear strain rate is not constant on the failure surface, even if the 


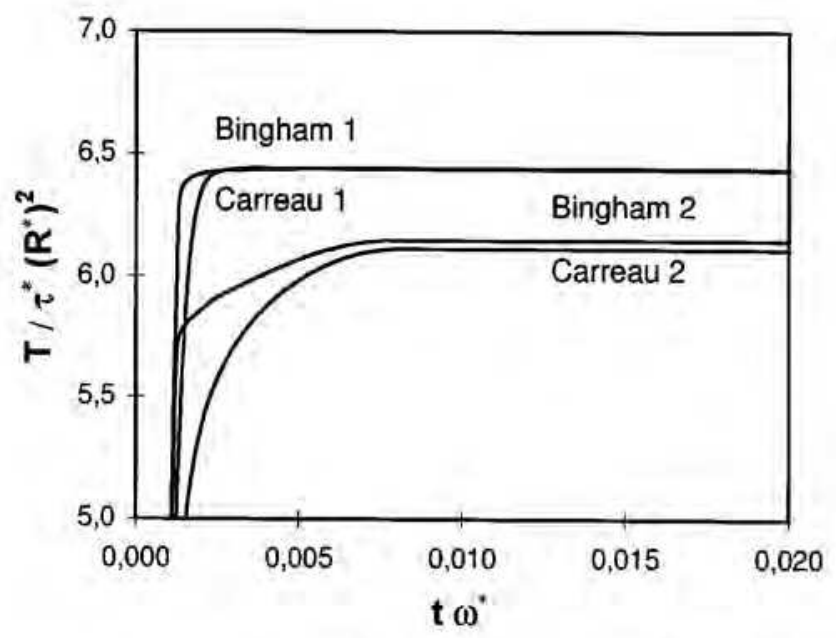

Figure 12. Dimensionless torque versus dimensionless time for the theoretical laws

Bingham 1 model is used, where dimensionless $\gamma$ varies from 31.3 at $\theta=45^{\circ}$ to 39.4 at $\theta=0$. This pattern is more pronounced when a wider shear strain rate localization zone is formed: when the Carreau 2 model is used dimensionless v varies from 5.5 to 35.4 at the failure surface. Nevertheless the usual assumption that shear strength is constant on the failure surface is quite correct because usually a wide range of $j$ has a narrow range of $\tau$. Models 2 simulations have a maximum diflerence of 10 per cent in $\tau$ at the failure surface (Table III).

Note that in Figure 9, constitutive laws are expressed in a dimensionless form, by means of angular velocity $\omega^{*}$. Thus for different values of $\omega^{*}$, different responses of shear strength are obtained, unless the type 1 model is used. If material behaviour depends on $\omega^{*}$, a type 2 model constitutive law should be expected, whereas a behaviour independent of $\omega^{*}$ is typical of type 1 models. That is, independence of $s_{u}$ from $\omega$ indicates that shear stress is constant in the range of shear strain rate applied. Note that this behaviour could change for other strain rate ranges, as in triaxial or viscosimeters lests.

\section{APPLICATION TO REAL MATERIALS}

Numerical simulation of vane test using constitutive laws estimated for actual materials has also been performed. Two materials have been considered: a slurry waste material called red mud and a soft clay. Both require the definition of a relationship between shear stress and shear strain rate. in order to use the above formulation.

\section{Red mud}

This material has been extensively studied by Nguyen and Boger. ${ }^{51} \mathrm{It}$ is a material produced in the extraction process of aluminium from bauxite. It consists of a mixture of oxides dissolved in plastic liquid which shows some special characteristics like tixotropy (links between particles broken due to the flow), yield stress and non constant viscosity. A particular red mud formed by 
VANE TEST

Table IV. Numerical values of the analyses of the vane test applied to Red Mud

\begin{tabular}{lccc}
\hline & Bingham & Casson & H-B \\
\hline $\max _{\theta=0^{\circ}}\left(v / R^{*} \omega^{*}\right)$ & 1.00 & 1.00 & 1.00 \\
$\max _{\theta=45^{\circ}}\left(v / R^{*} \omega^{*}\right)$ & 0.95 & 0.92 & 0.88 \\
$r / R^{*} \mid \max _{\theta=45^{\circ}}\left(v / R^{*} \omega^{*}\right)$ & 0.97 & 0.94 & 0.89 \\
$\max _{\theta=0^{\circ}}\left(\dot{\gamma} / \omega^{*}\right)$ & 39.33 & 38.67 & 37.32 \\
$\max _{\theta=45^{\circ}\left(\dot{\gamma} / \omega^{*}\right)}$ & 26.84 & 11.09 & 6.63 \\
$r / R^{*} \mid \max _{\theta=45^{\circ}}\left(\dot{\gamma} / \omega^{*}\right)$ & 1.01 & 1.01 & 1.01 \\
$\max _{\theta=0^{\circ}\left(\tau / \tau^{*}\right)}$ & 1.01 & 1.17 & 0.84 \\
$\max _{r / R^{*} \mid \operatorname{s5}^{\circ}\left(\tau / \tau^{*}\right)}$ & 1.01 & 1.13 & 0.75 \\
$T / \tau^{*}\left(R^{*}\right)^{2}$ & 1.01 & 1.01 & 1.01 \\
\hline & 6.51 & 7.37 & 4.96 \\
\hline
\end{tabular}

a concentration of 37.3 per cent of titanium oxide is simulated. Vane result and viscosimeter experimental values corresponding to that red mud are reported by Nguyen and Boger. ${ }^{51}$ Vane tests performed with vane radius equal to $1.3 \mathrm{~cm}$ and angular velocity equal to $0.1 \mathrm{cycles} / \mathrm{min}$ gave $\left(s_{\mathrm{u}}\right)_{\mathrm{vane}}$ of $126 \mathrm{~Pa}$. Viscosimeter experimental data and least-squares approximation by means of three different constitutive models are presented in Figure 13. The models used the Bingham, Casson and Herschel-Bulkley.

Table IV shows some numerical results of the analyses in order to compare the models employed (with $R^{*}=1.3 \mathrm{~cm}, \omega^{*}=0.1 \mathrm{cycles} / \mathrm{min}$ and $\tau^{*}=133.5 \mathrm{~Pa}$ ). Note that again $r=1.01$ is the radius at which the maximum shear strain rate and shear strength is produced irrespective of the model used. The applied torque values are very different. The reason for that is the range of shear strain rate mobilized during the test: 0-40 (dimensionless values) which correspond to $\dot{\gamma}=0-0.42 \mathrm{~s}^{-1}$. In the zoom of Figure 13, the different stress level for this range of $\dot{\gamma}$ is clearly highlighted. That zoom shows that a correct interpolation must be used to perform a correct analysis.

The value of $\left(s_{\mathbf{u}}\right)_{\text {vane }}$ calculated with Bingham model simulations, $136 \mathrm{~Pa}$, is quite similar to $\left(s_{\mathrm{u}}\right)_{\text {vane }}$ measured by Nguyen and Boger, ${ }^{51} 126 \mathrm{~Pa}$. Note that Bingham model has been approximated from experimental viscosimeter data at low shear strain rate, but still 10 times larger than the shear strain rate mobilized in the vane test. In general, extrapolation of experimental values from viscosimeters must be used carefully because the range applied in a vane test is very small when compared to that of a viscosimeter.

\section{Soft clay}

Soft clays have been extensively studied also by many researchers, but usually a soil mechanics point of view has been employed to define their behaviour. As a consequence of that, constitutive laws suggested for soft clays are presented usually in terms of a stress-strain relationship instead of a stress-strain rate one, even for clays with a high liquidity index. Most of the studies have been carried out using the conventional triaxial test, which can take from a few minutes to one or two hours. Hence rate effects are expected to be less important than in the vane test, where failure is reached in about one minute. Nevertheless, experimental results obtained in viscosimeters have 


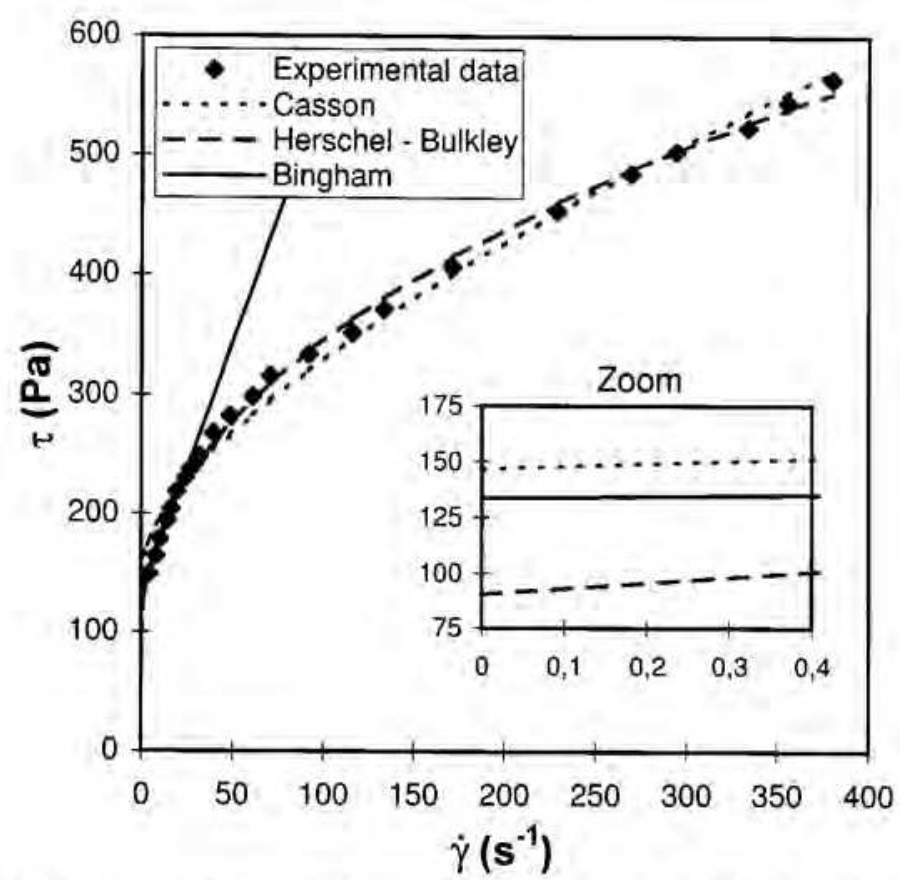

Figure 13. Shear stress $(\mathrm{Pa})$ versus shear strain rate $(1 / \mathrm{s})$ for the Red Mud constitutive laws

also been published (Figures 5 and 7), although its shear strain range is different from that used in the vane.

In order to obtain a general form of a shear stress-strain rate relationship, information about duration of triaxial tests and rate effects has been used. ${ }^{33.52,53} \mathrm{~A}$ logarithmic relation between shear stress and time to failure has been proposed by many researchers. Typical curves from Lacasse $^{52}$ are presented in Figure 14. Using strain rate as main variable, this relationship may be expressed as

$$
\tau / \tau_{\mathrm{r}}=a \log \left(; / ;_{\mathrm{r}}\right)+b
$$

where $\tau_{r}$ is the failure shear strength at reference time, $\dot{\gamma}_{r}$ is the failure strain rate at same reference time and $a, b$ are constants. If the test is performed at a constant strain rate, $\dot{\gamma}_{r}$ can be computed from the ratio shear deformation at failure vs. time to failure. Equation (23) shows the effect of increase in shear strength when the test is faster, which is a known behaviour for soft clays.

From the curves of Figure 14, a clay with the following constitutive law has been considered (assuming the reference time equal to $140 \mathrm{~min}$ and a 3 per cent of the failure shear deformation at that time):

$$
\text { Logarithmic model: } \tau / \tau^{*}=0.13 \log \left(\dot{\gamma} / \omega^{*}\right)+1.39
$$

where $\tau^{*}$ is a shear strength reference value and $\omega^{*}$ the rotation velocity that has been fixed to $12 \% \mathrm{~min}$. Also a Bingham and a Carreau models have been considered interpolating the 


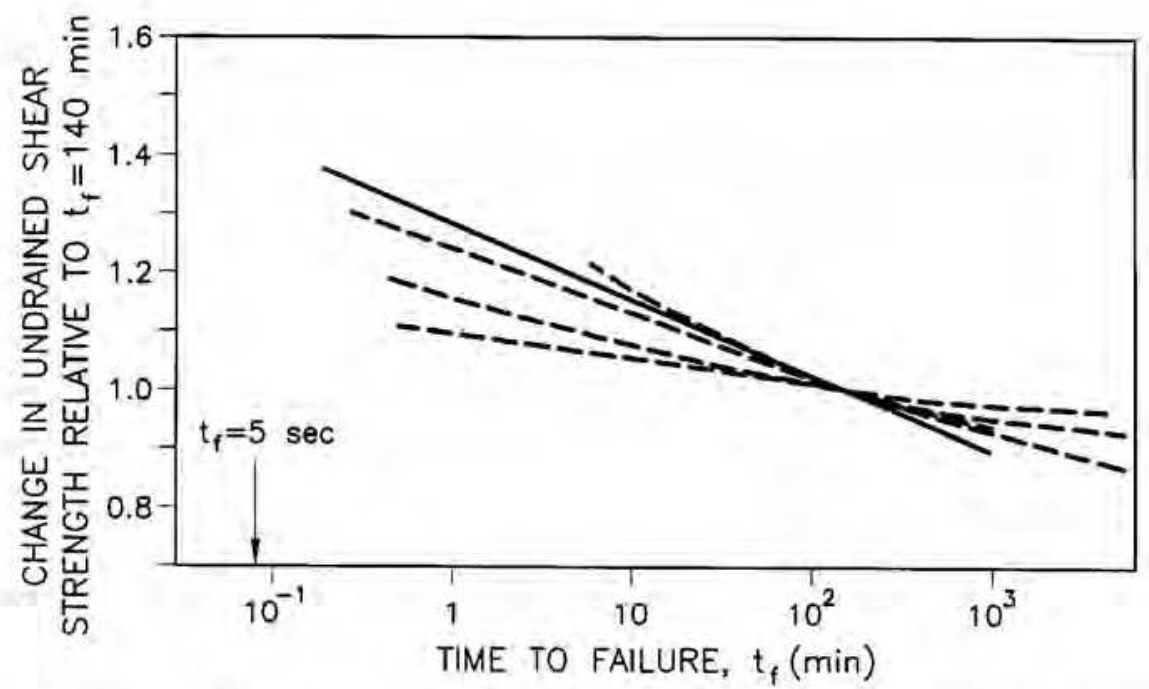

Figure 14. Summary of undrained rate effects in isotropically consolidated soils of different composition (after Lacasse ${ }^{57}$, Continuous line corresponds to the case analized in numerical simulations

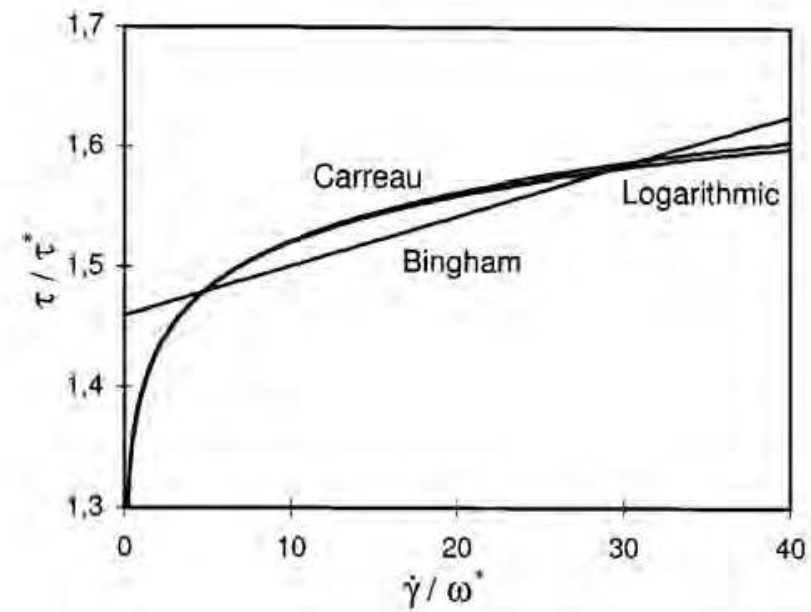

Figure 15. Dimensionless shear stress versus dimensionless shear st rain rate for the soft clay constitutive laws

Logarithmic one in the internal $\dot{\gamma} / \omega^{*} \in[0 \cdot 1,40]$ :

$$
\text { Bingham model: } \tau / \tau^{*}=1.46+0.0042 \dot{\gamma} / \omega^{*} \text {. }
$$

$$
\text { Carreau model: } \mu \omega^{*} / \tau^{*}=100\left(1+7200\left(\dot{\gamma} / \omega^{*}\right)^{2}\right)^{-0: 48}
$$

As in previous sections, Bingham and Logarithmic models have been approximated with a initial dimensionless viscosity of 100 , to avoid infinite viscosity values. Figure 15 shows the shear 